\title{
Evaluation of Antifertility Effects of Sperm Immobilization Factor from Escherichia coli on Male Mice
}

\author{
Aditi Chauhan $(1)$ and Vijay Prabha* \\ Department of Microbiology, Panjab University, Chandigarh - 160 014, India.
}

\begin{abstract}
Earlier in our laboratory, sperm immobilization factor (SIF) isolated from Escherichia coli has shown admirable contraceptive efficacy in female mice and thus generated interest in evaluating the same as a potential candidate for male contraception. Keeping this in mind, the present study was aimed at exploitation of SIF as contraceptive agent in male mouse model after intra testis administration. For this, Balb/c mice were administered with different concentrations $(10,50,100,200$, or $400 \mu \mathrm{g})$ of SIF and sacrificed on days 3,7,14,21,30,45,60, and 90 . After sacrifice, results in terms of change in body weight, tissue somatic indices, seminal parameters, histology, hematological parameters, lipid peroxidation, testosterone level, and cytokines level were evaluated. The weight profile and TSI of all experimental groups showed no significant change. In case of seminal parameters, $400 \mu \mathrm{g}$ of SIF led to azoospermia up to 90 days and tissue histology also revealed hypo-spermatogenesis. No significant change was observed in haematological parameters after SIF $(400 \mu \mathrm{g})$ administration however, a significant decrease was observed in testosterone levels. The oxidative status and cytokines profile was also affected after SIF $(400 \mu \mathrm{g})$ inoculation. Thus, when administered via intra testis route, SIF can lead to azoospermia and poses to be a potent and safe antifertility agent.
\end{abstract}

Keywords: Sperm immobilization factor, testis, azoospermia

\footnotetext{
*Correspondence: satishvijay11@gmail.com; +91 9417065675
}

(Received: December 6, 2021; accepted: January 4, 2022)

Citation: Chauhan A, Prabha V. Evaluation of Antifertility Effects of Sperm Immobilization Factor from Escherichia coli on Male Mice. J Pure Appl Microbiol. 2022;16(1):355-364. doi: 10.22207/JPAM.16.1.29

(C) The Author(s) 2022. Open Access. This article is distributed under the terms of the Creative Commons Attribution 4.0 International License which permits unrestricted use, sharing, distribution, and reproduction in any medium, provided you give appropriate credit to the original author(s) and the source, provide a link to the Creative Commons license, and indicate if changes were made. 


\section{INTRODUCTION}

The human population is burgeoning day by day, and it is estimated to reach up to a mark of 7 billion in $2050 .{ }^{1}$ As childbearing and rearing affect females' health and lifestyle directly, the research for effective and safe contraceptives has been focused only on them. Though there are various methods of contraception are available for women. Still, there are many cases where females cannot opt for a particular contraceptive choice due to lack of knowledge, social hesitation to ask or talk about them, and many have health issues. So, in those cases, the male partner must take full responsibility. ${ }^{2,3}$ There are only three contraceptive choices available for males, viz. withdrawal method, condoms, and vasectomy. They have their own lack as the withdrawal method is unreliable, condoms don't give $100 \%$ surety, and many male complaints about lack of pleasure with its use and vasectomy are irreversible. ${ }^{4-6}$ So, there is a dire need to look forward to new choices for male contraception. Scientists are working on it for many years and the two approaches they have taken forward for its development are hormonal approach in which they down-regulate the spermatogenesis by affecting the hormonal environment of the body while in non-hormonal approaches various chemicals and plant extracts are used to affect the spermatogenesis directly without affecting the hormonal environment of the body. Few of the hormonal studies and non-hormonal studies showed excellent results when human trials were carried out, but they had many side effects. ${ }^{7-9}$ Thus, limited their use in the public domain further. Rigorous research is still going on worldwide for a safe, reversible, and acceptable contraceptive method to complete this unmet reproductive health requirement. Amidst that, the exploitation of the rich diversity of microorganisms can be thought of. In this context, earlier, the SIF was isolated from Escherichia coli showing admirable spermicidal activity in-vitro and exquisite contraceptive efficacy in the female mice when administered intravaginally. ${ }^{10,11}$ These encouraging outcomes with the sperm impairing factor in female mice generated interest in evaluating the antifertility effect of SIF in male mice after intra testis administration.

\section{MATERIALS AND METHODS \\ Experimental Animals}

The experiments conducted in the present study comply with the Institutional Animal Ethics Committee of Panjab University vide letter no. PU/IACES/S/16/140. Every procedure followed in the study was as per the guidelines listed by the CPCSEA (Committee for the Purpose of Control and Supervision of Experiments on Animals). Sexually mature 5 to 6 weeks old Balb/c mice $(25 \pm 2 \mathrm{~g})$ were used for the experiments, and they were kept in isolated polypropylene cages. They were given water ad libitum and standard pellet food under standard conditions of the laboratory (dark: light cycle - 12:12).

\section{Microorganism}

E. coli strain causing in vitro sperm immobilization, previously isolated in our laboratory, was used in the present study.

\section{Sperm Immobilization Factor (SIF): Isolation and Purification}

From $72 \mathrm{~h}$ old $E$. coli cell culture, the SIF was isolated and purified using an earlier standardized method. ${ }^{10}$

Assessment of various parameters for evaluating contraceptive efficacy of sperm immobilization factor

\section{Inoculation procedure}

Male Balb/c mice ( $n=90)$ were surgically inoculated with different concentrations of SIF viz. $10,50,100,200$, or $400 \mu \mathrm{g}$ per $20 \mu \mathrm{l}$ under the anesthesia of ketamine and xylazine. The cocktail of $100 \mathrm{mg} / \mathrm{kg}$ of ketamine and $20 \mathrm{mg} / \mathrm{kg}$ of xylazine was intraperitoneally administered. The procedure started at least after $10 \mathrm{~min}$ of the anesthesia period. The duration of anesthesia was 45-60 min. The mice were monitored for breathing, heart rate, and body movements during the period. After 10 minutes of the anesthesia, the scrotal skin was washed gently with normal saline, followed by $80 \%$ ethanol with mice placed in the supine position. SIF was administered in the right testis of mice, in contrast, the left testis was considered as a control in every experimental group. For each concentration, three mice were euthanized by cervical dislocation on respective days viz. 3, 7,14, $21,30,45,60$ and 90 . Various parameters such as body weight, Tissue Somatic Indices (\%), seminal parameters and tissue histology were evaluated. 


\section{Tissue Somatic Indices (TSI) (\%) and Weight Profile}

The final and initial weight of the body was checked on the last day and the first day of the experiment, respectively. For TSI (\%), the mice were euthanized on respective day of sacrifice and different reproductive (testis, vas deferens, caudal epididymis), as well as the non-reproductive (bladder, spleen, liver, \& kidneys) organs, were removed, weighed, grossly examined, and TSI $($ TSI $(\%)=$ Organ weight/body weight $\times 100)$, was calculated.

\section{Seminal parameters Sperm count}

In order to determine the impact of SIF on the spermiogram, motility and sperm count were evaluated. After sacrifice, both the vas deferens were pulled and placed in prewarmed $200 \mu \mathrm{l}$ of PBS ( $50 \mathrm{mM}, \mathrm{pH} 7.2$ ), and gentle teasing was done to enable the spermatozoa to swim out in buffer on a glass plate. Further, $10 \mu \mathrm{l}$ of sample volume was examined under the light microscope (400X magnification) by placing it on a glass slide. To determine the sperm count, eight fields were scanned, and the mean of spermatozoa in every field was multiplied by a factor of $10^{6} .{ }^{12}$

\section{Sperm motility}

Following the method of Emmens, ${ }^{13}$ the motility was estimated, wherein on a warm slide, $10 \mu \mathrm{l}$ of the sample was placed, and motile and non-motile sperms were counted in eight different fields under a light microscope (400X), along with this motile sperm percentage was also estimated. Histological analyses

To elucidate the underlying mechanism of diminished reproductive potential and the effect of different concentrations of sperm immobilization factor on tissue morphology, histological analysis was done. For this, mice were euthanized on the respective day of sacrifice, and various non-reproductive and reproductive organs, viz. caudal epididymis, testes, vas deferens, kidney, liver, \& spleen, were collected and fixed for $24 \mathrm{~h}$ in $10 \%$ formaldehyde. Later, the tissues were then immersed in paraffin, and $4 \mathrm{~mm}$ sections were prepared. Further, these sections were stained using hematoxylin-eosin and observed for significant changes (400X magnification), if any.
The results obtained from above experiments revealed that SIF at a concentration of $400 \mu \mathrm{g}$ was capable of showing contraceptive effect for 90 days. Hence, for further experiments $400 \mu \mathrm{g}$ of SIF was chosen.

Evaluation of impact of SIF on haematological parameters, ALT, AST and testosterone Haematological parameters

For evaluating the haematological parameters, mice were divided into two groups viz. control group ( $n=3)$ and test group $(n=3)$, wherein the latter was administered with $400 \mu \mathrm{g}$ of SIF. In contrast, the control group was administered with $20 \mu \mathrm{l}$ of PBS. On day $90,600-800 \mu \mathrm{l}$ of blood was collected with cardiac puncture using a 22-25-gauge $\times 1$ " needle, 3-cc syringe, and stored in the vial coated with anticoagulant and analyzed for the haematological parameters. For measuring the AST (aspartate aminotransferase) and ALT (alanine aminotransferase), the blood was collected in a vial (without any anticoagulant coating) following the same method mentioned above, and the serum so obtained was analyzed following the method of Reitman and Frankel. ${ }^{14}$

\section{Testosterone assay}

To estimate the effect of SIF on serum level of testosterone, mice were divided into two groups viz. control group $(n=3)$ and test group $(n=3)$, administered with PBS $(20 \mu l)$ and SIF $(400 \mu \mathrm{g})$, respectively via intra testis route. The blood was collected in the vial without any anticoagulant coating, for serum collection, on day 90 as per the method as described earlier in haematological parameters. The testosterone serum level was measured by ELISA with the help of a commercial kit as per the instructions of the manufacturer. The assay sensitivity was $5 \mathrm{pg} / \mathrm{ml}$ with inter-and intra-assay coefficients with $5.1 \%$ and $7.5 \%$ variations, respectively. ${ }^{15}$

Evaluation of reactive oxygen species generation by the sperm impairing factors in testes

MDA, terminal product of lipid peroxidation and chief marker of oxidative damage, was estimated to determine the extent of peroxidation reaction in testicular tissue homogenates after administration of SIF. For this, mice $(n=6)$ administered with $400 \mu \mathrm{g}$ of SIF in the right testis and three mice were euthanized on $3^{\text {rd }}$ and $7^{\text {th }}$ day. Further, following the Ohkawa et al., method, ${ }^{16}$ the MDA levels were determined. 
Determination of local cytokine levels in the tissue homogenates of testis, following intra testis administration of sperm immobilization factor

The anti-inflammatory (IL-10) and pro-inflammatory (TNF- $\alpha$ ) cytokine levels were estimated to check the immunological effect of SIF. To quantify the same, male mice were divided into two groups, viz. control group $(n=15)$ receiving $\mathrm{PBS}$ and test group ( $n=15)$ receiving SIF (400 $\mu \mathrm{g})$. Three mice from each group were sacrificed on day $0,1,2,3$ and 4 . Testis of the right side was aseptically removed in $0.3 \mathrm{ml}$ of PBS and homogenized using a Teflon pestle. For 20 minutes, the homogenate was centrifuged at $5000 \mathrm{rpm}$, where a clear supernatant was achieved for estimating the cytokine levels. The IL-10 and TNF- $\alpha$ were estimated by following the protocols of the commercially available ELISA (EnzymeLinked Immunosorbent Assay) kit (Mouse IL-10 estimation kit, and Mouse TNF- $\alpha$ estimation kit
Ray Biotech, USA; Diaclone, France respectively). It was estimated that lower sensitivity levels for IL- 10 was $45 \mathrm{pg} / \mathrm{ml}$, and for TNF- $\alpha$, it was $60 \mathrm{pg} /$ $\mathrm{ml}$. Cytokines Levels were estimated in pico-grams per millilitre with reference to the standard curve plot using the test sample values.

\section{Statistical analysis of data}

The statistical significance was calculated by two-way ANOVA followed by Bonferroni test using GraphPad Prism v.5 (GraphPad Software Inc., La Jolla, CA, USA) software. The results were expressed as mean \pm standard deviation (SD). p-value $<0.05$ was considered to be statistically significant.

\section{RESULTS}

Sperm Immobilization Factor: Isolation and Purification

A standardized procedure was followed for the isolation and purification of SIF. ${ }^{10}$ Wherein, extraction of SIF was done by ammonium

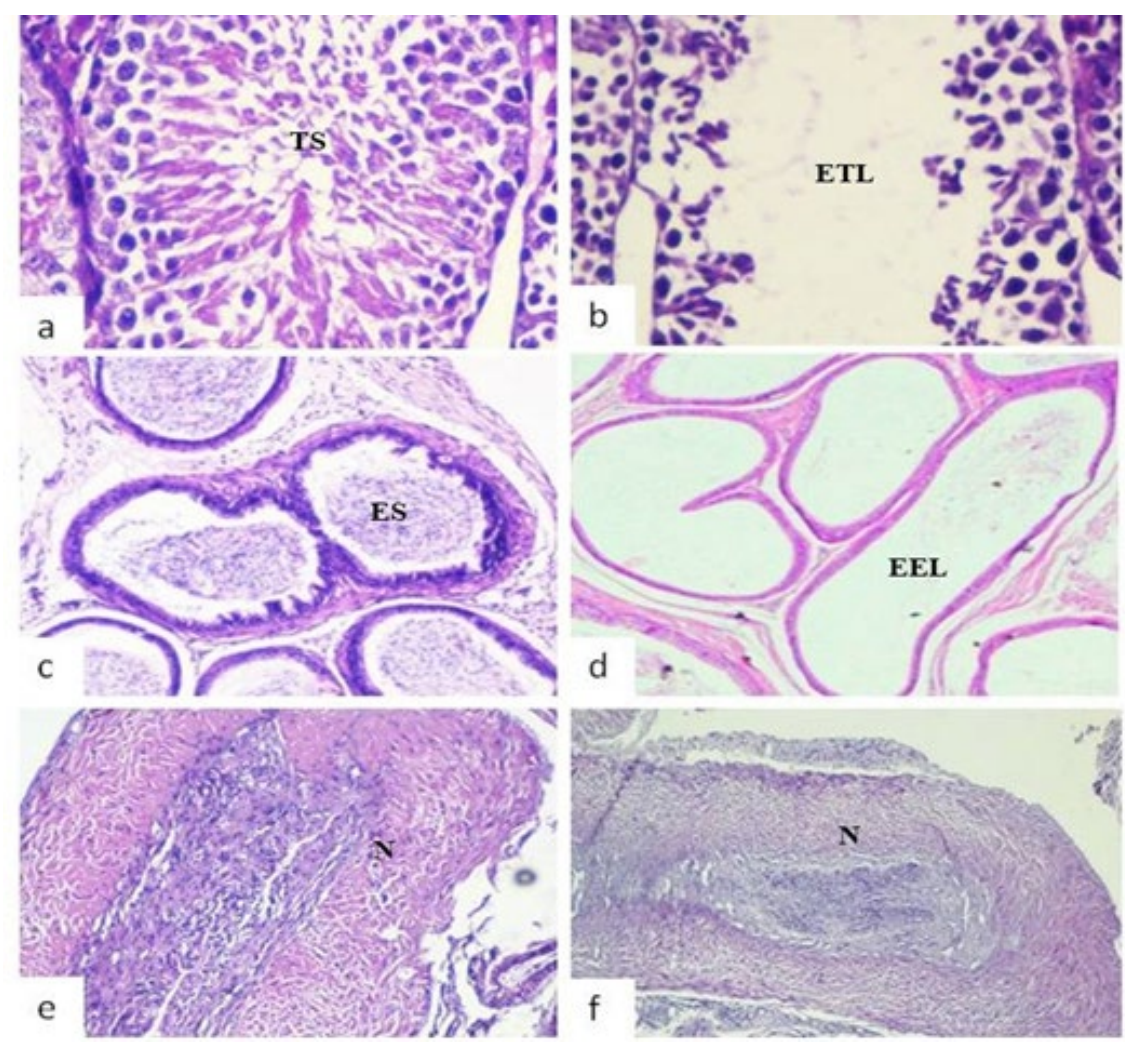

Fig. 1. Representative photomicrographs of histological examination (day 90) of reproductive organs viz. testis,

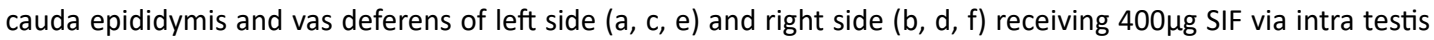
route. (TS: testicular spermatozoa; ES: epididymal spermatozoa; N: normal tissue histology; ETL: empty testicular lumen; EEL: empty epididymal lumen) 
sulphate precipitation, and thereafter purification was conducted using Sephadex G-200 column chromatography and subsequently by DEAEcellulose column chromatography. Finally, SDS PAGE was carried out for molecular weight confirmation (Suppl. Fig. 1, 2, and 3).

\section{Weight profile}

There were no significant changes observed in the weight profile after the administration of SIF in all the groups (suppl. Fig 4)

\section{Tissue Somatic Indices}

The TSI of reproductive and nonreproductive organs revealed no statistically notable change in all the groups receiving different SIF concentrations (Suppl. Fig. 5).

\section{Seminal parameters}

In case of seminal parameters, it was observed that the unilateral SIF administration
Table 2. Hematological parameters of male mice treated with SIF $(400 \mu \mathrm{g})$ via intra testis route (values in mean $\pm S D$ )

\begin{tabular}{lcc}
\hline & $\begin{array}{c}\text { Control } \\
\text { (PBS) }\end{array}$ & $\begin{array}{c}\text { Test } \\
(400 \mu \mathrm{g} \text { SIF) }\end{array}$ \\
\hline RBC $\left(10^{6} / \mathrm{mm}^{3}\right)$ & $8.31 \pm 0.05$ & $9.21 \pm 0.05$ \\
WBC $\left(10^{3} / \mathrm{mm}^{3}\right)$ & $4.1 \pm 0.29$ & $3.4 \pm 0.13$ \\
Hb $(\mathrm{g} / \mathrm{dl})$ & $12.1 \pm 0.03$ & $11.3 \pm 0.25$ \\
Lymphocytes (\%) & $86 \pm 0.03$ & $79 \pm 0.03$ \\
Monocytes (\%) & $5 \pm 0.31$ & $3.7 \pm 0.05$ \\
Neutrophils (\%) & $11 \pm 0.11$ & $8 \pm 0.01$ \\
Eosinophil (\%) & $0.1 \pm 0.05$ & $2 \pm 0.35$ \\
Basophil (\%) & $0.03 \pm 0.14$ & $1 \pm 0.01$ \\
AST (u/ml) & $39.1 \pm 2.01$ & $32 \pm 1.34$ \\
ALT (u/ml) & $31.2 \pm 0.21$ & $27 \pm 0.45$ \\
Testosterone (ng/ml) & $2.01 \pm 0.03$ & $0.73 \pm 0.03$ \\
\hline
\end{tabular}
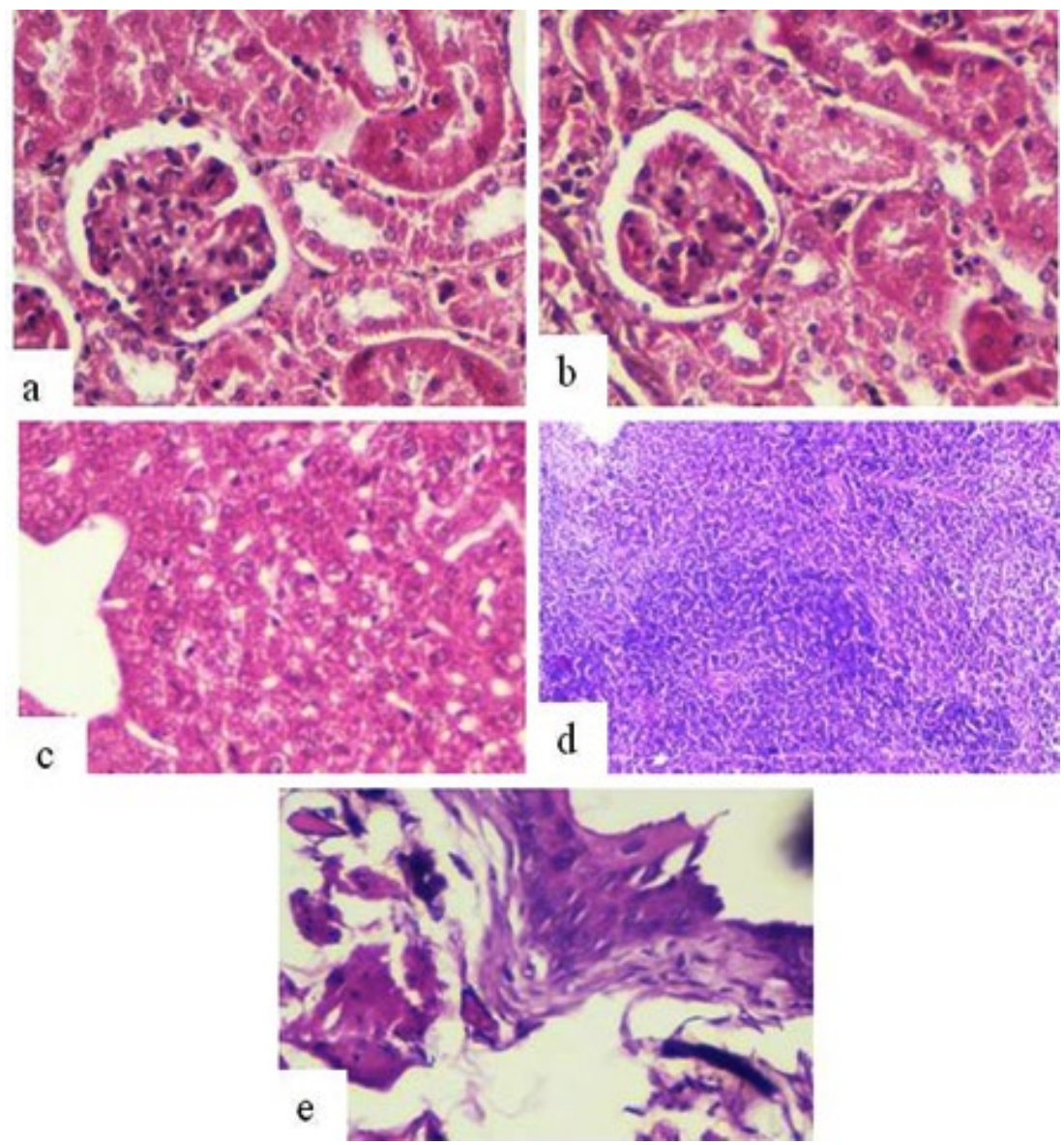

Fig. 2. Representative histological photomicrographs (day 90) of various non-reproductive organs of male mice receiving $400 \mu \mathrm{g}$ of SIF via intra testis route a) Left Kidney b) Right Kidney c) Liver d) Spleen and e) bladder showing normal histology. 
had sperm impairing effects on the treatment side, only that is the right side, whereas the left side showed no change as compared to the right side. In the case of male mice inoculated with $10 \mu \mathrm{g}$ of SIF, azoospermia persisted on the right side up to day 3 only, and thereafter it started to restore. While in case of male mice treated with $50 \mu \mathrm{g}$ of $\mathrm{SIF}$, the persistence of azoospermia lasted till the 7th day, and sperm count started to get restored after that. In case of male mice administered with 100 and $200 \mu \mathrm{g}$ of SIF, azoospermia persisted till day 21 and 45, respectively, after that sperm count began to revitalize. However, with $400 \mu \mathrm{g}$ of SIF, azoospermia could be achieved till day 90 in the right side (Table 1).

\section{Histological analyses}

The histological examination of mice inoculated with SIF $(400 \mu \mathrm{g})$ via intra testis route showed significant histological changes viz. empty epidydimal tubules and deteriorating alterations in seminiferous tubules, in the rightside reproductive organs (cauda epididymis, testis) (Fig. $1 \mathrm{~b}, \mathrm{~d}, \mathrm{f}$ ) in comparison to left side organs where tissue histology was found to be normal (Fig. 1 a,c,e). In contrast, vas deferens of both sides and all the non-reproductive organs (liver, kidney, spleen, bladder) showed normal tissue histology in all the groups (Fig. 2).

Haematological parameters

To evaluate the effect of SIF $(400 \mu \mathrm{g})$ on general health, the haematology and level of testosterone were assessed. The results showed no significant changes in the haematological parameters, levels of AST and ALT in the test receiving $400 \mu \mathrm{g}$ of SIF in comparison to the control receiving PBS (Table 2). While in the case of testosterone, a significant decrease $(p<0.01)$ was observed in the test group in comparison to the control group (Table 2).

\section{Lipid peroxidation}

To study if SIF induced any tissue damage, the chief levels of reactive aldehyde known as the MDA (malondialdehyde), developed by biomembranes peroxidation was estimated in testis, and it showed a highly significant increase in the MDA levels in the right testis administered SIF.

Table 3. Cytokine's level of male mice treated with SIF $(400 \mu \mathrm{g})$ via intra testis route

\begin{tabular}{lccccc}
\hline Days & Day 0 & Day 1 & Day 2 & Day 3 & Day 4 \\
\hline \multicolumn{7}{c}{ TNF- $\alpha$ levels $(\mathbf{p g} / \mathrm{ml})$} \\
Control group (PBS) & 115.5 & 186.1 & 181.05 & 176.21 & 172.16 \\
Test group (SIF) & 143.5 & 261.7 & 252.5 & 236.3 & 224.13 \\
& \multicolumn{7}{c}{ IL-10 (pg/ml) } \\
Control group (PBS) & 108.7 & 142.14 & 156.09 & 149.11 & 141.05 \\
Test group (SIF) & 132.27 & 187.6 & 198.15 & 241.23 & 227.22 \\
\hline
\end{tabular}

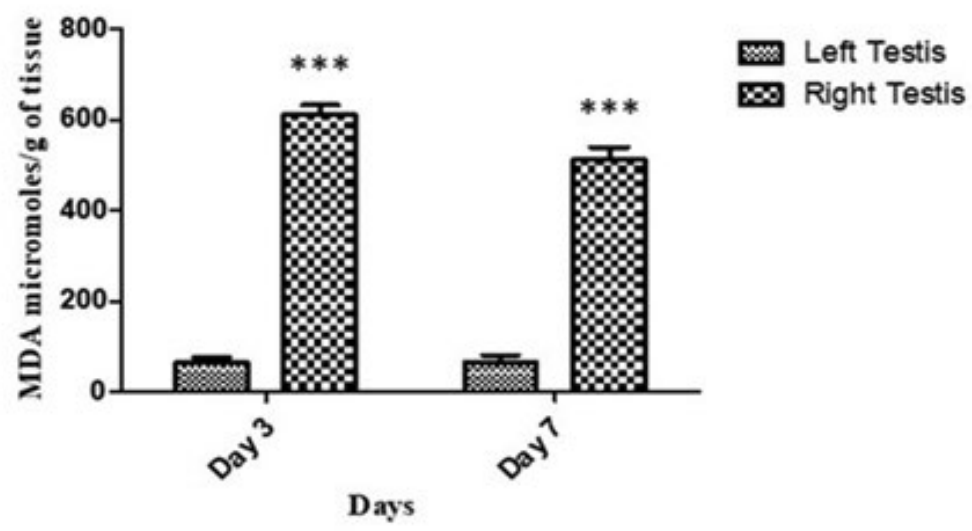

Fig. 3. Lipid peroxidation in terms of MDA ( $\mu$ moles/g of tissue) of testis in the right side in comparison to the left side on day 3 and 7 after administration with SIF via intra testis route. Data represents mean values \pm SD. $\left({ }^{*}\right),\left({ }^{* *}\right)$, $(* * *)$ represent $p<0.05, p<0.01, p<0.001$, respectively. 
The mean MDA ( $\mu \mathrm{mol} / \mathrm{g}$ of tissue) in right testis on day 3 and 7 were found to be $610.6 \pm 21.2$ and $512 \pm 17.5 \mu$ moles/g of tissue, respectively in comparison to the left side where the mean MDA levels were found to be $64.5 \pm 11.7$ and $68 \pm 16 \mu$ moles/g of tissue, respectively (Fig. 3).

Cytokines levels in the tissue homogenates of the testis

When the relationship between the level of cytokines and treatment of SIF was evaluated, the results revealed that there was a significant increase ( $p>0.001)$ in levels of TNF- $\alpha$ and IL-10 on all the days in comparison to control. Further, the profile showed that TNF- $\alpha$ reached to peak value on day 1 while the maximum level of IL-10 was observed on day 2 in every experimental group (Table 3).

\section{DISCUSSION}

In an attempt to study the antifertility effect of SIF for a longer-term, different doses of SIF were administered as a single dose via intra testis route and different parameters viz. body weight profile, TSI, seminal parameters, tissue histology, haematological parameters, testosterone serum level, lipid peroxidation, and cytokines level were examined at five different doses viz. 10, 50, 100, 200 , or $400 \mu \mathrm{g}$ for each mouse for 90 days.

The body and organ weight profile of male mice revealed no significant changes in all the experimental groups when administered with different SIF doses. Similar findings were also obtained in different animal models when administered with different antifertility compounds. ${ }^{17-22}$

Further, to study the minimum effective concentration of SIF that was capable of sustaining azoospermia throughout the 90 days of the observation period, different concentrations were administered, and seminal parameters were analyzed. The results revealed that $400 \mu \mathrm{g}$ of SIF led to azoospermia up to day 90 on the treated side. The results so obtained in case of seminal parameters after SIF administration were substantiated by the histological examination in which degenerative changes were observed in the seminiferous tubules of the treated side only. Similar findings were also obtained by Upadhyay et al. ${ }^{17}$ wherein unilateral administration of neem oil resulted in azoospermia only in the treated side.
To determine the effect of SIF $(400 \mu \mathrm{g})$ on general body health, haematological parameters were evaluated, and it showed no alterations in the haematological parameters and levels of ALT, AST in comparison to the mice receiving PBS, which signifies that SIF is nontoxic and induces anti-spermatogenic effects without affecting the general body metabolism. However, a significant decline in testosterone level in SIF administered group was observed in comparison with the control. As testosterone affects the epididymal milieu and assumes a significant role in spermatogenesis, ${ }^{23}$ so it is more likely that it had influenced the spermatogenesis; however, as hypo-spermatogenesis is discovered only on the right side, hence there might be other factors as well which have an important role.

In order to study other mechanisms that have played a role in SIF-induced inhibition of spermatogenesis in mice, oxidative status was evaluated. Oxidative stress is known as one of the renowned factors which influence both steroidogenesis and spermatogenesis in testis. The free radicals engendered due to oxidative stress disrupt the steroidogenic capacity of Leydig cells and germinal epithelium's ability to differentiate into normal spermatozoa. Alongside this, they likewise distress the cell membrane of spermatozoa on account of their immense level of polyunsaturated fatty acids. ${ }^{24,25}$ In the present study, distension in lipid peroxidation level was noted in the treated side in comparison with the non-treated side, suggesting oxidative stress in the treated side. Thus, the SIF-induced oxidative stress may also have contributed to the extermination of spermatogenesis.

Studies were extended further to determine if the presence of inflammation reflected in the cytokine profile of test mice. The results showed that in comparison to the control group, significant changes in both pro-inflammatory (TNF- $\alpha$ ) as well as the anti-inflammatory (IL-10) cytokines concentration were detected in testes homogenates of test mice collected on day $0,1,2$, 3 , and 4 . All these results provided evidence that diminished reproductive vigour in males might also be mediated by inflammation, ultimately damaging the male reproductive system. Since the unilateral SIF administration only affects the reproductive parts of the right side, it could be 
assumed that any systemic mechanism did not mediate spermatogenesis inhibition as it might affect the organs of both sides. However, in the future, apoptotic tools will be utilized to distinguish between apoptosis/necrosis in spermatogenic cells and more detailed studies will be conducted to figure out the other key molecular mechanisms involved behind the antifertility effect of SIF.

\section{CONCLUSIONS}

Taken together, the results of the aforementioned experiments have suggested that SIF exhibits an antifertility effect when administered via intra testis route. This might be by interfering with the steroidogenesis and/or by inducing oxidative stress and inflammation, resulting in spermatogenesis's annihilation without eliciting detectable toxic effects. Thus, it appears to be a promising contender for male contraception.

SUPPLEMENTARY INFORMATION
Supplementary information accompanies this
article at https://doi.org/10.22207/JPAM.16.1.29
Additional file: Additional Figs. S1 and S6.

\section{ACKNOWLEDGMENTS}

The authors would like to express their heartfelt thanks to Dr. B.N. Dutta (Retd. Pathologist, PGIMER, Chandigarh, India) for the histological analysis.

\section{CONFLICT OF INTEREST}

The authors declare that there is no conflict of interest.

\section{AUTHORS' CONTRIBUTIONS}

Both the authors have made a substantial, direct and intellectual contribution to the work, and approved it for publication.

\section{FUNDING}

The work was supported by Department of Science and Technology (DST), New Delhi, India (Grant number DST/Inspire Fellowship/2015/ IF150184).

\section{DATA AVAILABILITY}

All datasets generated or analyzed during this study are included in the manuscript and/or the Supplementary Files.

\section{ETHICS STATEMENT}

This study was carried out in accordance with the recommendations of the Committee for the Purpose of Control and Supervision of Experiments on Animals (CPCSEA). The protocol was approved by the Institutional Animal Ethics Committee of Panjab University, India under the protocol number PU/IACES/S/16/140.

\section{REFERENCES}

1. World Population Prospects 2019: Data Booklet. United Nations, Department of Economic and Social Affairs, Population Division. 2019. https://population.un.org/ wpp/Publications/Files/WPP2019_DataBooklet.pdf

2. Plana O. Male contraception: research, new methods, and implications for marginalized populations. Am J Men's Health. 2017;11(4):1182-1189. doi: $10.1177 / 1557988315596361$

3. Khourdaji I, Zillioux J, Eisenfrats K, Foley D, Smith R. The future of male contraception: a fertile ground. Transl Androl Urol. 2018;7(Suppl 2):S220-S235. doi: 10.21037/tau.2018.03.23

4. Mathew V, Bantwal G. Male contraception. Indian J Endocrinol Metab. 2012;16(6):910-917. doi: 10.4103/2230-8210.102991

5. Lampiao F. Coitus interruptus: are there spermatozoa in the pre-ejaculate? Int J Med Biomed Res. 2014;3:1-4.

6. Zhao R, Wu JQ, Li YY, Zhou Y, Ji H-L, Li Y-R. Efficacy of a combined contraceptive regimen consisting of condoms and emergency contraception pills. BMC Public Health. 2014;14:354. doi: 10.1186/1471-245814-354

7. Ducharme N. Male osteoporosis. Clin Geriatr Med. 2010;26(2):301-309. doi: 10.1016/j.cger.2010.02.005

8. Moulana M, Lima R, Reckelhoff JF. Metabolic syndrome, androgens, and hypertension. Curr Hypertens Rep. 2011;13(2):158-162. doi: 10.1007/s11906-011-0184-0

9. Mishra RK, Singh S, Singh SK. Natural products in regulation of male fertility. Indian J Med Res. 2018;148:S107-S114. doi: 10.4103/ijmr.IJMR_1968_17

10. Prabha V, Sandhu R, Kaur S, et al. Mechanism of Sperm Immobilization by Escherichia coli. Adv Urol. 2010;2010:240268. doi: 10.1155/2010/240268

11. Answal M, Prabha V. Escherichia coli recombinant sperm immobilizing factor $\operatorname{RecX}$ as a potential vaginal contraceptive. Reprod Biol Endocrinol. 2018;16:88. doi: 10.1186/s12958-018-0407-1

12. World Health Organization. Laboratory Manual for the Examination and Processing of Human Semen, $5^{\text {th }}$ ed. World Health Organization. 2010:1-286. https:// www.who.int/docs/default-source/reproductivehealth/srhr-documents/infertility/examination-andprocessing-of-human-semen-5ed-eng.pdf 
13. Emmens CW.The motility and viability of rabbit spermatozoa at different hydrogen ion concentrations. J Physiol. 1947;106(4):471-481. doi: 10.1113/ jphysiol.1947.sp004228

14. Reitman S, Frankel S. A colorimetric method for determination of serum glutamate oxaloacetate and glutamic pyruvate transaminase. Am J Clin Pathol. 1957;28(1):56-63. doi: 10.1093/ajcp/28.1.56

15. Santos EW, de Oliveira DC, Hastreiter A, et al. Hematological and biochemical reference values for C57BL/6, Swiss Webster and BALB/C mice. Braz J Vet Res An Sci. 2016;53(2):138-145. doi: 10.11606/ issn.1678-4456.v53i2p138-145

16. Ohkawa H, Ohishi N, Yagi K. Assay for lipid peroxidation in animal tissues by thiobarbituric acid reaction. Anal Biochem. 1979;95(2):351-358. doi: 10.1016/00032697(79)90738-3

17. Upadhyay SN, Dhawan S, Talwar GP. Antifertility effects of Neem (Azadirachta indica) oil in male rats by single intra-vas administration: An alternate approach to vasectomy. J Androl. 1993;14(4):275-281.

18. Jana K, Samanta PK, Ghosh D. Evaluation of single intratesticular injection of calcium chloride for nonsurgical sterilization of male Black Bengal goats (Capra hircus): a dose-dependent study. Anim Reprod Sci. 2005;86(1-2):89-108. doi: 10.1016/j. anireprosci.2004.05.021
19. Singh A, Singh SK. Reversible antifertility effect of aqueous leaf extract of Allamanda cathartica L. in male laboratory mice. Andrologia. 2008;40(6):337-345. doi: 10.1111/j.1439-0272.2008.00866.x

20. Chauhan A, Agarwal M. Evaluating the antifertility potential of an aqueous extract from Cassia fistula seeds in male rats. Fertil Steril. 2010;93(5):1706-1710. doi: 10.1016/j.fertnstert.2009.09.001

21. Reddy KVR, Gupta SM, Aranha CC. Effect of antimicrobial peptide, Nisin, on the reproductive functions of rats. ISRN Vet Sci. 2011;2011:828736. doi: 10.5402/2011/828736

22. Ramya MC, Shivabasavaiah, Shivanandappa T. Reversible antifertility effect of Opuntia elatior Mill. fruit extract. Int I Reprod Contracep Obstet Gynecol. 2015;4:392-397. doi: 10.5455/2320-1770. ijrcog20150421

23. Smith LB, Walker WH. The regulation of spermatogenesis by androgens. Sem Cell Dev Biol. 2014;30:2-13. doi: 10.1016/j.semcdb.2014.02.012

24. Hales DB, Allen JA, Shankara T, et al. Mitochondrial function in Leydig cell steroidogenesis. Ann $N$ Y Acad Sci. 2005;1061(1):120-134. doi: 10.1196/ annals.1336.014

25. Aitken RJ, Roman SD. Antioxidant systems and oxidative stress in the testis. Oxid Med Cell Longev. 2008;1(1):1524. doi: 10.4161/oxim.1.1.6843 